laws and company policies on ICT-enabled work from outside the employer's premises.

The questionnaires for each country can be roughly divided into three groups, corresponding to the kind and quality of data sources used. Only limited pre-existing data on the topic could be made available in Brazil, Hungary, and India. Nationwide surveys on working from home and the use of ICT (generally as part of the labour force or working conditions surveys) in a more general sense were the main data source for the studies from Argentina, the US and the European countries. Surveys on T/ICTM in particular comprised the main data source for the report from Japan.

Statistics on T/ICTM were generated, to varying degrees, across these countries. What seems to fuel this variation is differing levels of interest in the topic among policymakers and public authorities. Policymakers and public authorities generally initiate and support research on T/ICTM in order to promote the adaptation of existing work arrangements and labour markets to the 'information age'. The actual adoption of $\mathrm{T} /$ ICTM among employers and employees seems to play a smaller role.

The information from Europe is complemented with data from the sixth wave (2015) of the European Working Conditions Survey (EWCS). The objectives of the EWCS are: (a) to measure working conditions across European countries on a harmonised basis; (b) to analyse relationships between different aspects of working conditions; (c) to identify groups at risks and issues of concern, as well as areas of progress; (d) to monitor trends over time; and (e) to contribute to European policy development, in particular on quality of work and employment issues. The survey included 43850 face-to-face interviews with workers - both employees and the selfemployed. Both descriptive and multivariate analysis have been developed to investigate the incidence of, and associations between, T/ICTM, working time, work-life balance and health and well-being (Eurofound, 2015a)6. In the analysis of the EWCS included in this report, only employees are included.

Results The incidence of T/ICTM is related not only to technological developments in different countries but also to existing economic structures and cultures of work. The countries analysed in this report with high shares of T/ICTM include Finland, Japan, the Netherlands, Sweden and the US.

Overall, the incidence of T/ICTM varies substantially, from $2 \%$ to $40 \%$ of employees, depending on the country, occupation, sector and the frequency with which employees engage in this type of work. Across the EU28, an average of about $17 \%$ of employees are engaged in T/ICTM. In most countries, larger proportions of workers carry out T/ICTM occasionally rather than on a regular basis. T/ICTM is more common among professionals and managers, but is also significant among clerical support and sales workers. In relation to gender, in general men are more likely to perform T/ICTM than women. However, women carry out more regular home-based telework than men. This suggests that country-specific gender roles and models of work and family life play a role in shaping T/ICTM.

Regarding the positive effects of T/ICTM, workers report a reduction in commuting time, greater working time autonomy leading to more flexibility in terms of working time organisation, better overall work-life balance, and higher productivity. Companies benefit from the improvement in work-life balance, which can lead to increased motivation and reduced turnover as well as enhanced productivity and efficiency, and from a reduction in the need for office space and associated costs. The disadvantages of T/ICTM are the tendency to lead to longer working hours, to create an overlap between paid work and personal life (work-home interference), and to result in work intensification. Home-based teleworkers seem to report better work-life balance, while 'high-mobile' workers are more at risk of negative health and well-being outcomes. Partial and occasional forms of T/ICTM appear to result in a more positive balance between the benefits and drawbacks. From a gender perspective, women doing T/ICTM tend to work shorter hours than men, and women seem to achieve slightly better work-life balance effects.

Discussion T/ICTM are highly ambiguous and perhaps even contradictory. Specifically, it appears that T/ICTM is not unequivocally advantageous compared to traditional office work at the employer's premises. Neither does it seem to result in mainly negative effects. On the positive side, workers report a reduction in commuting time, greater autonomy in working time organisation, better overall work-life balance and higher productivity. The disadvantages of T/ICTM with which workers seem to struggle the most are its tendency to extend working hours, create an overlap between paid work and personal life due to a blurring of work-life boundaries, and also lead to the intensification of work. It appears that many of these ambiguous or paradoxical effects have to do with the interactions among ICT use, the place of work in specific work environments and the characteristics of different occupations. Moreover, whether T/ICTM substitutes for work in the office, or instead supplements it, appears to be an important factor affecting whether the reported outcomes are positive or negative.

\section{7c IMPACT OF DIGITALISATION ON OCCUPATIONAL SAFETY AND HEALTH - AN EU-OSHA FORESIGHT}

${ }^{1}$ Emmanuelle Brun, ${ }^{1}$ Kate Palmer, ${ }^{1}$ Katalin Sas, ${ }^{1}$ Annick Starren, ${ }^{2}$ Xabier Irastorza*. ${ }^{1}$ Prevention and Research unit, EU-OSHA; ${ }^{2}$ European Agency for Safety and Health at Work, Spain

\subsection{6/oemed-2018-ICOHabstracts.624}

Introduction Digitalisation of the economy will fundamentally change the types of jobs available, forms of employment, where we work and how we work. This in turn may give rise to new and emerging OSH challenges that must be anticipated.

Methods EU-OSHA implemented a scenario-building 'foresight on new and emerging OSH risks associated with ICT by 2025', including on-line platforms, robotics and artificial intelligence, in two steps:

- Identification of key trends and drivers of change through horizon scanning and expert consultation;

- Development and testing of scenarios through an interactive process with stakeholders.

Follow-up expert review papers and study were commissioned on challenges highlighted in the foresight.

Results 92 Societal, Technological, Economic, Environmental and Political (STEEP) trends and drivers of change were identified and used to develop four scenarios on the future world of work and the new and emerging OSH risks associated with ICT. Each scenario presents different OSH challenges and opportunities. Expert review papers were prepared on crowdsourcing, robotics, 3-D printing, monitoring technologies and 
the e-retail sector. A follow-up study 'Regulating the OSH impact of the online platform economy' describes the related OSH risks, highlights the challenges for current regulatory approaches on OSH and presents examples of approaches being developed to meet these challenges.

Discussion The future can evolve in different directions shaped by the actions and decisions of various players taken today. EU-OSHA intends to inform and stimulate debate on the future of work among experts and policy-makers to ensure safe and healthy workplaces in the future.

\section{7d FUTURE OF WORK AND OCCUPATIONAL HEALTH - A GLOBAL VIEW FROM THE ILO}

Nancy Leppink. International Labour Organisation, Switzerland

\subsection{6/oemed-2018-ICOHabstracts.625}

Introduction Summary and key 'takeaways' from ILO global conversations on the Future of Work and their implications for occupational safety and health

Discussion Over that last two years the ILO has support global conversations on the Future of Work. These conversations have focused on four topics:

- work and society,

- jobs of the future,

- organisation of work and production, and

- governance of work.

These conversations identified for key drivers of changes in the world of work -technology, demography, climate change and globalisation. Each of these conversations and the drivers of change they identified have implications for occupational safety and health and the strategies that have been developed over the last decades to improve the safety and health of work and workplaces - from government regulation to workplace management systems. For decades, we have been reacting to the growing body of evidence on work-related hazards and their impact on workers' health and safety. Our energies have been focused on retrofitting work and workplaces to eliminate hazards after significant harm has already been done.

And as the body of evidence on occupational safety and health hazards has grown and its scope expanded beyond physical, biological, and chemical hazards, to psychosocial hazards and hazard related to work organisation, we must now presume that all work has an impact on worker health and safety and when we create the future of work we can no longer have 'a wait and see' attitude. We must anticipate the impact that future jobs will have on the safety and health of workers and this responsibility does not rest only with governments, employers and workers but with technology developers, equipment and chemical manufacturers, architects and the workplace designers, and human resource professionals as well as OSH professionals. For the ILO this may mean rethinking how it develops OSH standards and supports their implementation by its Member States.

\section{1 PROMOTING OSH STRATEGIES FOR GLOBAL END TB EFFORTS AMONG SILICA-EXPOSED WORKERS AND HEALTHCARE WORKERS}

MA Fingerhut, P Gottesfeld. International Commission on Occupational Health (ICOH)

10.1136/oemed-2018-ICOHabstracts.626

Aim of session Tuberculosis is the greatest public health challenge today. The global health community is actively planning strategies to End TB by 2030, and the occupational health community can play an important role in contributing solutions to prevent TB in high-risk worker populations. This session will review the evidence for the high prevalence of TB among health care workers and silica-exposed workers and outline the practical strategies for reducing these risks. Partners will be sought to engage governments and global health funders to invest in prevention strategies, and to offer assistance to countries in the future to carry out the OSH actions.

Despite decades of global efforts to end tuberculosis (TB), it is still 9th in the top ten causes of death globally, with 10.4 million new cases occurring in 2016. In September 2018 the UN General Assembly will hold a high-level meeting on TB. A preparatory Global Ministerial Meeting was held in Moscow in November 2017. Because it is well established that occupational risk factors contribute to the $\mathrm{TB}$ epidemic, $\mathrm{ICOH}$ participated in the Moscow Meeting. ICOH members reached out to health ministers to include occupational safety and health $(\mathrm{OSH})$ measures to prevent $\mathrm{TB}$ cases by reducing respirable silica dust exposures and taking actions to protect healthcare workers from occupational TB infections. This $\mathrm{OSH}$ focus adds additional approaches to the current focus on improving effective medication, which also prevents new TB cases. The Moscow Declaration now includes health care workers, care givers, miners and other workers exposed to silica dust as high risk TB populations. In some high burden TB countries, health care workers have almost a 4-fold incidence of TB compared to the general population. Studies have shown that silica dust exposure increases risk of acquiring TB up to 4-fold, and combined silicosis and HIV in miners increases risk of acquiring active TB by 15 times. Because respirable silica is an IARC Group 1 carcinogen, reduction prevents both cancer and TB. Discussions at the Moscow Meeting appreciated the addition of $\mathrm{OSH}$ preventive measures. However, more effort is required to bring governments and global health funders on board to recognise that working conditions and silica dust are significant risk factors for TB that must be addressed as part of a comprehensive strategy. To take these efforts forward, ICOH has formed two Stop TB component efforts: TB-HCW and Silica-TB. Discussions in this Workshop will bring together partners and plans to succeed.

\section{1a PREVENTING TUBERCULOSIS WITH SILICA DUST CONTROLS}

P Gottesfeld. Occupational Knowledge International, San Francisco, CA USA

10.1136/oemed-2018-ICOHabstracts.627 